Nancy Everhart

Florida State University

everhart@fsu.edu

\title{
Capturing the Information-seeking of Students Employing a Wearable Camera: Discussions of Applications in School Libraries
}

\begin{abstract}
Utilizing wayfinding, think-aloud protocol (TAP), retrospective think-aloud protocol (RTAP), and a wearable camera, the actions, thoughts and feelings of an autistic college freshman and a neurotypical peer are recorded as they navigate their campus library in search of materials. The library website, virtual maps to resource locations, and library workers served equally as enablers and barriers to both students in their information seeking. This proof of concept study demonstrates that participant viewpoint ethnography is a viable research methodology that could be applied in school libraries for both neurotypical and autistic students .
\end{abstract}

Keywords: wayfinding, think-aloud protocol, school library, information seeking

\section{Introduction}

Considerable research on students' information-seeking has centered on librarians but not on the students themselves. Utilizing wayfinding, think-aloud protocol (TAP), retrospective think-aloud protocol (RTAP), and a wearable camera, the actions, thoughts and feelings of students can be captured as they navigate libraries in search of materials (Everhart and Escobar, 2018).

\section{Statement of the Research Problem}

Current literature regarding students information-seeking lacks first-person accounts. This exploratory study investigated, through the first-person perspective of an autistic student and a neurotypical peer, supports and services academic libraries currently provide that assist in the fulfillment of information needs and is framed by the following research questions:

1. What wayfinding cues aid in decision-making within academic library environments for a student with autism compared to a neurotypical peer?

2. What barriers hinder wayfinding in academic library environments for a student with autism compared to a neurotypical peer?

3. How are decisions classified for a student with autism compared to a neurotypical peer in academic library environments? 
4. How do the resulting behaviors during the execution of a plan of action in information-seeking relate to success for a student with autism compared to a neurotypical peer?

\section{Literature Review}

Wayfinding theory, identified by Lynch (1960) and modified by Passini (1981), states that human wayfinding behaviors are influenced by different factors of the physical environment in the navigation of large buildings such as libraries and shopping malls, including differentiation of the environment, visual access, and complexity of the spatial layout (Li \& Klippel, 2017). A researcher may observe a user in an environment but not understand the thought processes involved in reaching their destination nor the paths they took to get there (Mandel, 2013).

One method that has accurately captured the user experience of college students in the academic library employed a wearable unobtrusive camera (GoPro) strapped to the subjects to capture both their navigational experience and thought processes while completing tasks such as finding specific periodicals and reference books (Kinsley, Schoonover, \& Spitler, 2016). GoPro cameras and other personal viewpoint devices allow the subject to "own" their view yet manage to capture multiple aspects of an environment (Chalfen, 2014). Studies outside of library and information science using this methodology, called participant viewpoint ethnography (PVE), include Chrysanthi, Berggren, Davies, Earl, and Knibbe (2016) observing archaeologists "in the wild"; Ghekiere et al.'s (2015) study using GoPro cameras to record environmental elements children encounter while cycling for transportation; and Wilhoit and Kisselburgh (2016) examination of PVE as a method of data collection.

In addition to recorded observations, to fully comprehend how an individual navigates or wayfinds in their physical environment, it is necessary to understand their thought processes and which information they use to make decisions. Think-aloud protocol (TAP) is a method that prompts users to articulate their thoughts and reasons behind how they approach a certain task (Battleson, Booth, \& Weintrop, 2001). Although some studies have used TAP with disability populations (Chandrashekar, Fels, Stockman, \& Benedyk, 2006), to date there has been no research involving students on the autism spectrum. As persons with disabilities may compensate cognitively for their deficit, modifications such as encouraging subjects to speak aloud and prompting them each time they were silent for more than 15 seconds have been found to be successful with this population (Chandrashekar et al., 2006).

Retrospective think-aloud protocol (RTAP), which permits the user to revisit their experiences after the observation to elaborate further on thoughts or emotions that did not feel they adequately expressed in the moment, further enriches studies of navigating the library environment. Given that characteristics of autism can include difficulty in conversational pragmatics and social communication, and turn-taking with simultaneously writing, the use of 
RTAP allows subjects to clarify what they may not have been able communicate in real-time while completing their task (Paul, Orlovski, Marcinko, \& Volkmar, 2009).

TAP combined with wayfinding has proven to be a successful research method allowing for first-person expression of thoughts and feelings experienced in the academic library environment but not school libraries. Likewise, it has not been employed in research with autistic persons, it holds promise for this population - particularly when used in conjunction with RTAP to reveal what information seeking is like for students on the autism spectrum (Passini, Rainville, Marchand, \& Joanette, 1998).

\section{Methodology}

This study engaged two students, one neurotypical and one with autism, in completing five information-seeking tasks in an academic library. The tasks involved 1) Locating a journal article on the shelf in bound periodicals; 2) Finding a book; 3) Checking out a laptop; 4) Reserving a study room; and 5) Printing out a specific article from the library's databases. In a typical school library, finding a book and printing out an article could easily be replicated but the other tasks probably would not.

\section{Research Protocol}

Upon entering the library and meeting the researcher individually, each student signed their consent form and was fitted via chest strap with a GoPro camera. The students were instructed to affix the device to themselves in the manner most comfortable for them. Once they were comfortable with the camera, the subject pressed the record button to test recording their experience. Both subjects only required about two minutes of practice in order to feel comfortable with the equipment. This procedure was also pilot-tested to ensure success. It could be posited that high school students, and perhaps even younger students, would be similarly comfortable with this familiar device.

Participants were told that the researcher would be accompanying them on their searching experience and would prompt them to think-aloud, expressing their thoughts and feelings as they accomplished each information seeking task. The students were also informed that their performance in terms of success of their wayfinding were not being judged and that the research was more focused on their thought process during information seeking, especially whether supports in place in the academic library environment were helping or hindering their pursuits.

Throughout their wayfinding activities, the students were accompanied by the researcher, who provided them with their tasks, printed individually on $2 \times 8$ slips. The researcher took notes with pen and paper throughout the wayfinding event to gather any thoughts or ideas prompted by the observation of the participants. The remaining data were captured in their entirety by the GoPro camera. 


\section{Think-aloud Protocol}

TAP was employed to ascertain participants' thoughts and feelings as they searched for the items. As the subjects navigated through the wayfinding activities, the researcher solicited verbalization of their thought processes and emotions conjured by prompts such as but not limited to:

1. How are you feeling at this moment?

2. You appear . Tell me what you are thinking right now?

3. How did you decide what to start with?

\section{Retrospective Think-aloud Protocol}

Because one subject self-disclosed as being autistic, a diagnosis hallmarked by communication impairments, subjects were encouraged to talk about their experiences if they fell silent for an extended period as their executive functioning thought process was focused on the completion of the wayfinding tasks versus verbalization. Once the subjects completed their tasks, the researcher then played back the GoPro footage collected by the subject on a laptop computer screen. Using RTAP, and questions developed by Hahn and Zitron (2011) as a context, the researcher prompted responses from the participants, asking questions such as:

1. What were you thinking/feeling in that moment that you did not express?

2. What would have helped you find the items easier?

3. What was the most challenging part of finding the items?

4. What helped you locate the items?

5. You seemed at this moment. Tell me more about what you were thinking/feeling?

In addition to the notes taken during the TAP and RTAP, the GoPro camera footage also yielded dialogue which was transcribed. Qualitative thematic coding was employed to the transcripts, allowing the researcher to compare the data collected to the research questions identified prior to the study. Such analysis of these first-person experiences recorded by the GoPro device offered insight into themes relating to which wayfinding elements of cues and decision-making by an autistic college student attempting to navigate the academic library in comparison to his neurotypical peer.

\section{Informed Consent and Ethical Considerations}

Students were required to sign an informed consent form and were apprised that the GoPro would be capturing their interactions with the library environment and that the camera would only capture their voice and outward facing perspective. Anonymity and confidentiality were insured and the participants' names or other identifying information were not connected to the recordings. As ethnographic research using a GoPro camera can raise the concern of bystanders of their capture on film, waivers were supplied to any bystander at risk of being filmed and the option was given for their countenance to be removed from the recording. Informed consent would also be required in a school setting. 


\section{Findings and Discussion}

For the purposes of this discussion, the focus will be on the tasks of finding a book on the shelf (task 2) and printing out a specific article from the library's database (task 5) which as noted previously would be performed in most secondary school libraries.

The students approached task two very differently (Table 1) although both applied skills acquired during task one (locating a journal article on the shelf in bound periodicals). Thomas (neurotypical) was confident in searching for the book using OneSearch ${ }^{1}$ as he had been previously directed by a student worker. Elliott (autistic), having built a rapport with the student worker in the first task, felt comfortable immediately approaching her again with the citation given in task two. Both students found the call number to be more helpful to them in finding the book on Darwin than the title of the volume itself and both students did not encounter barriers that prevented them from finding the book relatively quickly. Thomas was more self-sufficient in his search for the resource and followed the directions he found via the map on OneSearch without issue. Interestingly, while Thomas wrote the directions to the book on his task slip, Elliot took pictures of the location information on the computer screen with his smartphone. Both students completed task two in a comparable period of time.

\section{Table 1}

Task 2: Find the book: A Calendar of the Correspondence of Charles Darwin, 1821-1882, Frederick Burkhardt and Sydney Smith. 1993. Cambridge University Press, New York: NY. Call Number: QH31.D2 C15.

\begin{tabular}{|c|c|c|}
\hline & Thomas (NT) & Elliot (ASD) \\
\hline Cues & $\begin{array}{l}\text { - Article title search on computer } \\
\text { - "Find it at [redacted]" for finding } \\
\text { the book location in university } \\
\text { library } \\
\text { - Previous experience with finding } \\
\text { articles in main library } \\
\text { - } \text { Book citation } \\
\text { - Call number of book } \\
\text { - Title of book } \\
\text { - Map of resource location }\end{array}$ & $\begin{array}{l}\text { - } \text { Book citation } \\
\text { - Call number of the book }\end{array}$ \\
\hline Barriers & & $\begin{array}{l}\text { - Student worker can't direct him to } \\
\text { the exact location }\end{array}$ \\
\hline
\end{tabular}




\begin{tabular}{|c|c|c|}
\hline Decisions & $\begin{array}{l}\text { Decides to search for book by call } \\
\text { number versus title } \\
\text { - Asks for help from student } \\
\text { worker }\end{array}$ & $\begin{array}{l}\text { - Asks for help from student worker } \\
\text { Decides that the student worker } \\
\text { has provided sufficient } \\
\text { information to begin search } \\
\text { - Decides to accept help from } \\
\text { special collections librarian who } \\
\text { offers it }\end{array}$ \\
\hline & Thomas (NT) & Elliot (ASD) \\
\hline Behaviors & $\begin{array}{l}\text { Relies on student worker to find } \\
\text { resource on the website and its } \\
\text { exact location (row number, etc.) } \\
\text { - Follows directions to the resource } \\
\text { provided by the map }\end{array}$ & $\begin{array}{l}\text { - Relies on student worker to find } \\
\text { resource on the website and its } \\
\text { exact location (row number etc.) } \\
\text { but accepts that they cannot find it } \\
\text { - Takes a photo of computer screen } \\
\text { with library floorplan } \\
\text { - Accepts help from librarian }\end{array}$ \\
\hline $\begin{array}{c}\text { Time to } \\
\text { Completion }\end{array}$ & $4: 30$ & $5: 30$ \\
\hline
\end{tabular}

In task 5, both Thomas and Elliot used the library computers to find the relevant article to download and print but faced different barriers (Table 2). For Thomas, the cost of printing was a deterrent that did not appear to worry Elliot. While Thomas found the correct article straightaway, Elliot's search was confused by multiple resources appearing in his search with the same title.

\section{Table 2}

Task 5: Find the journal article on the library website in .pdf format: Pastor, S., Semikoz, V. B., \& Valle, J. W. F. (1998). Low-energy anti-neutrinos from the sun. Physics Letters B, 423(1), 118-125. Call Number: 530.5 P578, pt. B. Print this article on one of the available library printers.

\begin{tabular}{|c|c|c|}
\hline & Thomas (NT) & Elliot (ASD) \\
\hline Cues & $\begin{array}{l}\text { - Previous experience with the library } \\
\text { website } \\
\text { - Previous experience with library } \\
\text { computers } \\
\text { - Print dialog box }\end{array}$ & $\begin{array}{l}\text { - Previous experience with the } \\
\text { library website } \\
\text { - Previous experience with library } \\
\text { computers } \\
\text { - Print dialog box } \\
\text { - Signage with printing } \\
\text { instructions posted next to } \\
\text { printing computers } \\
\text { - Previous experience printing at } \\
\text { the library }\end{array}$ \\
\hline
\end{tabular}




\begin{tabular}{|c|c|c|}
\hline Barriers & $\begin{array}{l}\text { - Sign on the computer: "For Catalog } \\
\text { Only" } \\
\text { - Concern over cost of printing }\end{array}$ & $\begin{array}{l}\text { - Multiple entries per resource in } \\
\text { OneSearch }\end{array}$ \\
\hline Decisions & $\begin{array}{l}\text { - Decides to use the library website to } \\
\text { find the resource } \\
\text { - Decides not to print the article }\end{array}$ & $\begin{array}{l}\text { - Decides to use the library } \\
\text { website to find the resource } \\
\text { - Decides to print the article }\end{array}$ \\
\hline Behaviors & $\begin{array}{l}\text { - Goes to printers where article would } \\
\text { be printed }\end{array}$ & $\begin{array}{l}\text { - Goes to the printers to show he } \\
\text { knows where printed article } \\
\text { would be accessed and goes } \\
\text { through the motions }\end{array}$ \\
\hline & Thomas (NT) & Elliot (ASD) \\
\hline $\begin{array}{l}\text { Time to } \\
\text { Completion }\end{array}$ & 5:09 & 3:00 \\
\hline
\end{tabular}

Wayfinding cues and barriers experienced by the neurotypical student and the autistic student were very similar. Both were aided in their wayfinding by prior personal experience with the library computers and the library website. Signs also aided the students on their journey, especially those situated within their line of sight, in agreement with Hahn and Zitron's (2011) affirmation that existing signage assists students in navigating the library. For example, Thomas noticed that he could not use the same computer he had been using to search for an electronic version of the article in task five to download and print as a sign was affixed to the computer monitor saying "Catalogue Use Only." Elliot found signage helpful on the same task when he noticed instructions for printing affixed to the carrel hosting the printing computer and the printer. Both students felt that they would have been assisted in their wayfinding by maps posted on the various floors of the library yet were guided by maps found online through OneSearch.

Librarians and student workers were found by Hahn and Zitron (2011) to be a useful resource for students as they navigated the stacks. Student workers seated at the circulation desk were also wayfinding cues for the student however, they were used more readily by Elliot (autistic) than they were by the neurotypical student, Thomas. Thomas waited longer to initially consult the student workers for assistance as he seemed to enjoy the challenge of searching for resources assigned via the tasks by using the library website and OneSearch. His consultation with the student workers was last resort in nature, only when he was certain that he could not find the resources on his own. Initially, Elliot also took time to extensively search the library website and OneSearch while completing task one, yet once he found the student worker to be helpful and trustworthy, he returned for their assistance on subsequent tasks without hesitation.

"Social communication challenges constitute a major concern in postsecondary educational environments where individuals are expected to communicate effectively and comfortably with their peers and college faculty without supervision" (Zager \& Alpern, 2010, p. 151). Previous 
autism-related studies contend that college students with ASD may exhibit difficulty engaging in reciprocal social interaction, issues and anxiety associated with maintaining real-time / face-to-face conversations, and difficulty interpreting nonverbal cues as such traits are core diagnostic features of autism (Barnhill, 2016; Pinder-Amaker, 2014; Zager \& Alpern, 2010). In this study, Elliot did not hesitate to engage the student worker with his friendliness and was not ashamed to admit that he needed help in his wayfinding. This openness to interaction, contrary to literature about autism characteristics, was unexpected yet aided Elliot immensely in his wayfinding experience in the academic library. Use of the student workers also highlights the differences in the students' decision-making processes, with Elliot deciding to trust and seek the assistance of the workers early on in his wayfinding experience whereas Thomas preferred to wade through the library website, seek signage, and rely on previous library experiences as information resources.

Another wayfinding aid which differed between the cases was Elliot's use of his smartphone to capture information shared with him by the student workers. While Thomas relied on his supplied pen and paper to take down the locations of the volumes in tasks one and two, Elliot made use of his phone's camera to capture the information provided to him by the student workers. Elliot made repeated use of these captured images as he searched the stacks, referring to them almost repetitiously as an information resource. Persons with autism use smartphones to assist them in various tasks (Vlachou \& Drigas, 2017) and this may have been a natural extension of previous activities or a coping mechanism that was taught previously.

Barriers in wayfinding were also discovered to be similar between the cases. Most notable was the enormity of search results presenting in task five. Searching for the journal article on the shelf, as well as an electronic version of the same article for printing, proved overwhelming for Thomas and Elliot as many different versions of the same article presented themselves in OneSearch, whether those versions be conference proceedings, the bound volume of the periodical on the shelf, or various versions hosted by different subscription databases. Finding the exact version of the article to fulfill the wayfinding task required strict attention to detail, which was equally problematic for both students. This difficulty corresponds to Battleson et al.'s (2001) assertion that "the staggering amount of information available via these sites can produce a kind of 'information overload' that can bewilder, confuse, and even discourage users" (p. 189). A barrier to wayfinding which was expected to be more challenging to the student with ASD was the high volume of students using the library computer stations. For many students with autism who value familiarity and routine, this need to change course and find another available computer could have been traumatic, yet Elliot determined the availability of additional computers by using signage. Knowing the schedule for the computer classroom, and the times the computers were reserved, gave him the confidence needed to resume wayfinding. 
Both students were ultimately successful in completing the five tasks. Their wayfinding was aided by prior knowledge, transfer of knowledge, signage, computer cues, and library staff. The major differences between the neurotypical student and the student with autism was that the student with autism used library staff, photos, and talking himself through tasks for information seeking, and the neurotypical student relied more on the library's website.

Barriers in wayfinding were also discovered to be similar between the cases. Most notable was the enormity of search results presented in task five.

\section{Conclusions}

Students' wayfinding in an academic library was aided by prior knowledge, transfer of knowledge, signage, computer cues, and library staff. The major differences between the neurotypical student and the autistic student was that the student with autism used library staff, photos, and talking himself through tasks for information seeking, and the neurotypical student relied more on the library's website. This differed as to what had been expected.

A significant contribution of this study is the inclusion of an autistic student. This accords with the website banner of the Autistic Self Advocacy Network, "Nothing about us without us" (http://autisticadvocacy.org/), including participation in research studies. It also conveys the thoughts and feelings of a young adult with ASD, which is important according to Cox et al. (2015):

Although recent efforts to break the silence about Autism (e.g., Autism awareness day/month, "Autism Speaks" website), the voices of individuals with ASD - particularly those who have the interest in and ability to succeed in college - have been drowned out by the overwhelming emphasis (both in the general public and the scholarly literature) on early identification and intervention for young children with autism. By giving voice to a growing population of students who have strong potential for postsecondary success, research empowers autistic individuals to self-advocate as they consider opportunities for continued educational advancement (p. 28).

PVE employing a wearable camera to record information seeking, as well as clarifying thoughts responsible for decisions and behaviors via TAP and RTAP, demonstrated that this is a viable research methodology for both neurotypical college students and those with autism. Because there is relatively little empirical literature available on ASD student success in academic libraries or college in general, this study contributes to an essential knowledge base that can inform policies and practices implemented by academic libraries. Such an expanded knowledge base is critical, as the development of effective interventions is dependent upon researchers' comprehensive understanding of the varied and complex set of factors that facilitate or impede the information seeking success of individuals with ASD. 


\section{Applications in School Libraries \\ Research}

Students involved in this study reported enjoying the experience immensely. They felt "important" contributing to research and had no issues with wearing the GoPro camera and liked the unique approach. Such devices have become ubiquitous in the daily lives of young adults and children and are being used more frequently - even with toddlers (Caton and Hackett, 2019). There is no reason to suspect this would not be feasible with children - even autistic ones - in school libraries.

It would be straightforward to develop tasks related to school assignments or student interests. Some examples are: evaluation of online sources, detecting fake news, browsing behavior, citing sources and citation management, working in teams, personal information seeking, and transfer of skills to a public library setting, among others. This would be more relevant as the tasks in this study were isolated and mechanical in order to provide a proof-of-concept of the methodology. As in this study, the method could be used to compare variables such as achievement level, gender, age, technology proficiency, etc.

Researchers need to determine the developmental level of student subjects when considering think-aloud and retrospective think-aloud techniques. There have been reports of these techniques being used with children as young as six (van Someren, Barnard, \& Sandberg, 1994) often in studies of usability (Charoenpruksachat \& Longani, 2021) or self-regulated learning (Vandevelde, Van Keer, Schellings, \& Van Hout-Wolters, 2015).

\section{Practice}

School libraries are typically smaller and less complex than academic libraries but some of the same enablers and barriers found in this study could also be encountered or employed there. Useful signage, maps that are integrated with the online catalog, successful past experiences, and helpful staff were found to be enablers in locating a book on the shelf and printing a specific periodical article. Likewise, discerning a relevant citation from a large number of search results and the cost of printing may also be barriers in schools. School librarians teach students how to discern relevancy, and could instruct them how to save relevant articles to a management system rather that print them or not impose economic barriers (American Library Association, 2006).

Students in this study were more successful when they enlisted the help of library staff. School librarians could provide a great service to college-bound students if they served as a role model of helpfulness, educated students about the role of college librarians, and encouraged them to ask for help when needed. 


\section{Acknowledgements}

This research was supported by a grant from the Institute of Museum of Library Services, Grants. No. RE- 31-16-0129-16 "PROJECT A+ : Students with ASD in the Academic Library: Coaching to Enhance Implementation of Librarian Professional Development." We thank Charlie Remy and Paul Wyss for their assistance in creating our wayfinding tasks.

\section{References}

American Library Association. (2006, July 26). Economic barriers to information access: An interpretation of the library bill of rights. Advocacy, Legislation \& Issues. http://www.ala.org/advocacy/intfreedom/librarybill/interpretations/economicbarriers

Barnhill, G.P. (2016). Supporting students with Asperger syndrome on college campuses: Current practices. Focus on Autism and Other Developmental Disabilities, 31(1), 3-15. https://doi-org/10.1177/1088357614523121

Battleson, B., Booth, A., \& Weintrop, J. (2001). Usability testing of an academic library web site: A case study. Journal of American Librarianship, 27, 188-198. https://doi.org/10.1016/S0099-1333(01)00180-X

Chalfen, R. (2014). “Your panopticon or mine?" Incorporating wearable technology's Glass and GoPro into visual social science. Visual Studies, 29(3), 299-310. https://doi-org/10.1080/1472586X.2014.941547

Charoenpruksachat, A., \& Longani, P. (2021). Comparative study of usability evaluation methods on a hyper casual game. 2021 Joint International Conference on Digital Arts, Media and Technology with ECTI Northern Section Conference on Electrical, Electronics, Computer and Telecommunication Engineering, 153-156. https://doi.org/10.1109/ECTIDAMTNCON51128.2021.9425717

Chrysanthi, A., Berggren, Å., Davies, R., Earl, G.P., \& Knibbe, J. (2016). The camera "at the trowel's edge": Personal video recording in archaeological research. Journal of Archaeological Method and Theory, 23(1), 238-270. https://doi-org/10.1007/s10816-015-9239-x

Caton, L. \& Hackett, A. (2019). Head mounted, chest mounted, tripod or roaming? The methodological potentials of a GoPro camera and ontological possibilities for doing visual research with child participants differently in Kucirkova, N., Rowsell, J., \& Falloon, G. (Eds.). The Routledge international handbook of learning with technology in early childhood (1st ed.). Routledge. https://doi.org/10.4324/9781315143040

Chandrashekar, S., Fels, D., Stockman, T., \& Benedyk, R. (2006). Using think-aloud protocol with blind users: A case for inclusive usability evaluation methods. Proceedings of the International ACM SIGACCESS Conference on Computers and Accessibility, 8, 251-252. https://doi.org/10.1145/1168987.1169040

Cox, B.E., Thompson, K., Anderson, A., Mintz, A., Locks, T., Morgan, L., \& Wolz, A. (2017). College experiences for students with autism spectrum disorder: Personal identity, public 
disclosure, and institutional support. Journal of College Student Development, 58(1), 71-87. https://doi:10.1353/csd.2017.0004.

Everhart, N. \& Escobar, K. (2018). Conceptualizing the information-seeking of college students on the autism spectrum through participant viewpoint ethnography. Library and Information Science Research, 40(3-4), 269-276.

https://doi.org/10.1016/j.lisr.2018.09.009

Ghekiere, A., Van Cauwenbergh, J., de Geus, B., Clarys, P., Cardon, G., Salmon, J., \& Deforche, B. (2015). Assessing cycling-friendly environments for children: Are micro-environmental factors equally important across different street settings? International Journal of Behavioral Nutrition and Physical Activity. 12(1), 54. https:// doi.org/10.1186/s12966-015-0216-2

Hahn, J., \& Zitron, L. (2011). How first-year students navigate the stacks. Reference \& User Services Quarterly, 51(1), 28-35. http://dx.doi.org/10.5860/rusq.51n1.28

Kinsley, K.M., Schoonover, D., \& Spitler, J. (2016) GoPro as an ethnographic tool: A wayfinding study in an academic library. Journal of Access Services, 13(1), 7-23. http://doi.org/10.1080/15367967.2016.1154465

Li, R., \& Klippel, A. (2017). Wayfinding in libraries: Can problems be predicted? Journal of Map and Geography Libraries, 8(1), 20-38. https://doi-org/10.1080/15420353.2011.622456

Lynch, K. (1960). The image of the city. Boston, MA: MIT Press.

Mandel, L.H. (2013). Finding their way: How public library users wayfind. Library and Information Science Research, 35(3), 264-271. http://dx.doi.org/10.1016/j.lisr.2013.04.003

Passini, R. (1981). Wayfinding: A conceptual framework. Urban Ecology, 5(1), 17-31. https://doi.org/10.1016/0304-4009(81)90018-8

Passini, R., Rainville, C., Marchand, N., \& Joanette, Y. (1998). Wayfinding and dementia: Some research findings and a new look at design. Journal of Architectural and Planning Research, 15(2), 133-151.

Paul, R., Orlovski, S.M., Marcinko, H.C., \& Volkmar, F. (2009). Conversational behaviors in youth with high-functioning ASD and Asperger syndrome. Journal of Autism and Developmental Disorders, 39(1), 115-125. https://doi:10.1007/s10803-008-0607-1

Pinder-Amaker, S. (2014) Identifying the unmet needs of college students on the autism spectrum. Harvard Review of Psychiatry, 22(2), 125-137. https://doi.org/10.1097/hrp.0000000000000032

van Someren, M.W., Y.F. Barnard, Y.F. \& Sandberg, J.A.C. (1994). The think-aloud method: A practical approach to modelling cognitive processes. Psychology Research Institute, 1994

Vandevelde, S., Van Keer, H., Schellings, G., \& Van Hout-Wolters, B. (2015). Using think-aloud protocol analysis to gain in-depth insights into upper primary school children's 
self-regulated learning. Learning and Individual Differences, 43, 11-30.

https://doi.org/10.1016/j.lindif.2015.08.027

Vlachou, J.A., \&Drigas, A.S. (2017). Mobile technology for students \& adults with autistic spectrum disorders (ASD). International Journal of Interactive Mobile Technologies, 11(1), 4-17. https://dx.doi.org/10.3991/ijim.v11i1.5922

Wilhoit, E.D., \& Kisselburgh, L.G. (2016). Through the eyes of the participant: Making connections between researcher and subject with participant viewpoint ethnography. Field Methods, 28(2), 208-226. https://doi.org/10.1177/1525822X15601950

Zager, D., \& Alpern C. (2007). Addressing communication needs of young adults with autism in a college-based inclusion program. Education and Training in Developmental Disabilities, 42(4), 428-436. 